\title{
Establishment and characterization of a multi-purpose large animal exposure chamber for investigating health effects
}

\author{
Cite as: Rev. Sci. Instrum. 90, 035115 (2019); doi: 10.1063/1.5042097 \\ Submitted: 29 May 2018 - Accepted: 4 March 2019 • \\ Published Online: 28 March 2019
}

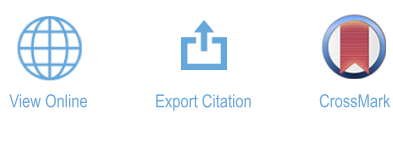

Xinze Peng, ${ }^{1,2}$ Mia R. Maltz, ${ }^{2,3}$ Jon K. Botthoff, ${ }^{2,3}$ Emma L. Aronson, ${ }^{2,4}$ Tara M. Nordgren,,$^{2,5}$ David D. Lo, ${ }^{2,5,5)}$ (D) and David R. Cocker ${ }^{1,2, b)}$

\begin{abstract}
AFFILIATIONS
${ }^{1}$ Department of Chemical and Environmental Engineering, Bourns College of Engineering, Center for Environmental Research and Technology, University of California Riverside, 1084 Columbia Ave, Riverside, California 92507, USA

2BREATHE (Bridging Regional Ecology, Aerosolized Toxins, \& Health Effects) Center, University of California Riverside, 900 University Ave, Riverside, California 92521, USA

${ }^{3}$ Center for Conservation Biology, University of California Riverside, 900 University Ave, Riverside, California 92521, USA

4Department of Microbiology and Plant Pathology, University of California Riverside, 900 University Ave, Riverside, California 92521, USA

${ }^{5}$ Division of Biomedical Sciences, School of Medicine, University of California Riverside, 900 University Ave, Riverside, California 92521, USA
\end{abstract}

a) Author to whom correspondence should be addressed: David.Lo@medsch.ucr.edu

${ }^{b}$ Electronic mail: dcocker@engr.ucr.edu

\begin{abstract}
Air pollution poses a significant threat to the environment and human health. Most in vivo health studies conducted regarding air pollutants, including particulate matter (PM) and gas phase pollutants, have been either through traditional medical intranasal treatment or using a tiny chamber, which limit animal activities. In this study, we designed and tested a large, whole-body, multiple animal exposure chamber with uniform dispersion and exposure stability for animal studies. The chamber simultaneously controls particle size distribution and PM mass concentration. Two different methods were used to generate aerosol suspension through either soluble material (Alternaria extract), liquid particle suspension (nanosilica solution), or dry powder (silica powder). We demonstrate that the chamber system provides well controlled and characterized whole animal exposures, where dosage is by inhalation of particulate matter.
\end{abstract}

Published under license by AIP Publishing. https://doi.org/10.1063/1.5042097

\section{INTRODUCTION}

Air pollution is the presence in the outdoor atmosphere of one or more contaminants, which include particulates, gases, vapors, compounds, or biological materials in quantities, characteristics, and durations that are either damaging to property or injurious to human, plant, or animal life. Particulate matter (PM), including PM2.5 (particulate matter with aerodynamic diameter less than $2.5 \mu \mathrm{m}$ ) and coarser particles like dust and pollens, is major atmospheric air contaminant that continues to a pose significant threat to human health. ${ }^{1-3}$ In recent years, extensive studies have investigated the resultant health effects of exposure to PM on human and model organisms. Numerous epidemiological studies have consistently demonstrated that air pollution is strongly associated with the morbidity and mortality from multiple cardiopulmonary and lung diseases; results indicate that PM2.5 has far more impacts on health than heretofore recognized. ${ }^{4-9}$ One major factor is the relatively high deposition fraction of particles smaller than $2.5 \mu \mathrm{m}$ in all regions of the lungs. PM2.5 will even reach the alveoli while inhaled nanoparticles can pass from the lungs into the bloodstream and extrapulmonary organs. Studies in mice have demonstrated an accumulation in the blood and liver following pulmonary exposure to a broader size range of $2-200 \mathrm{~nm} .^{10}$ 


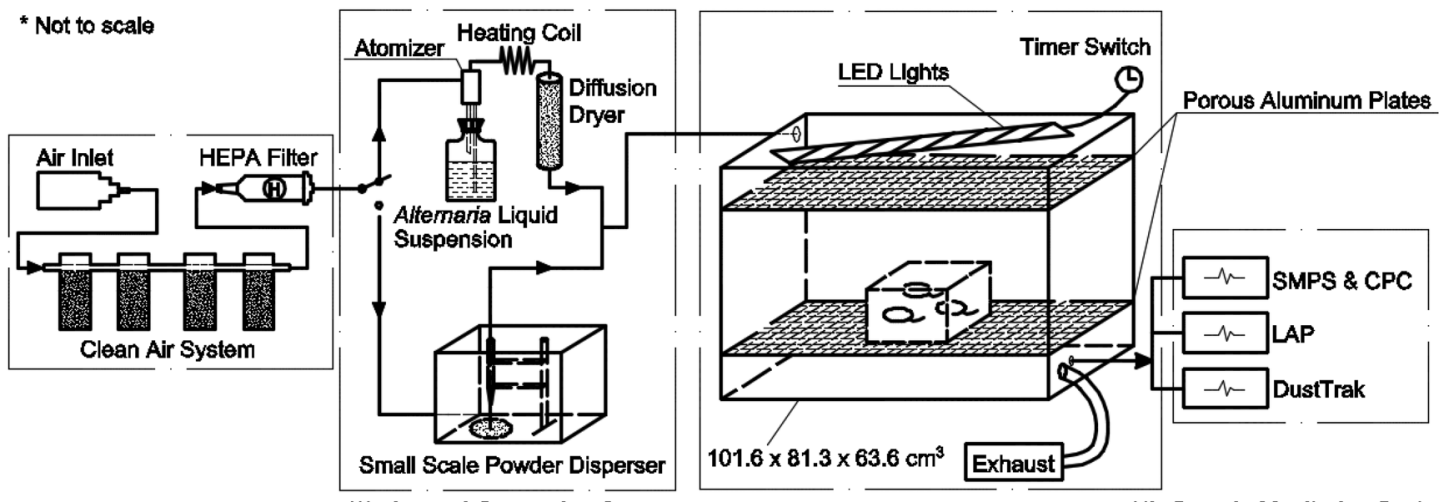

(1) Clean Air System

(2) Aerosol Generation System

(3) Chamber System

(4) Sample Monitoring System

FIG. 1. Schematic of the chamber system, including four main components: (1) clean air system, (2) aerosol generation system, (3) chamber system, and (4) sample monitoring system.

This chamber system allows for a route of exposure that simulates naturally occurring inhalation, as opposed to the most common method to study mouse exposures to environmental challenges. In fact, intranasal delivery may not be representative of common exposures. During an intranasal treatment, a mouse is held in a supine position while a micropipette is placed at the external nares and a concentrated solution is trickled in slowly. ${ }^{11,12}$ Heightened concerns regarding the use of intranasal treatment, and its lack of relevance to common human exposure modes, has motivated our research aimed at exposing mice via inhalation in this study.

For better understanding the health impacts of air pollution exposure, we constructed a large-scale chamber for exposure to multiple pollutants. Featuring on whole-body exposure, this chamber houses up to 18 mice in separate cages for each experiment (Fig. 1) with its large dimension of $540 \mathrm{l}$, which is much larger than other chambers (Table I). ${ }^{13-16}$ Compared to other chronic exposure chambers featuring nose-only exposures that limit the animal activities and only allow short term exposure for each test, ${ }^{17-19}$ our chamber frees the mice in a natural way of inhalation and delivers 7 consecutive days of exposure until the need of changing beddings or adding food supplies. Using our chamber system, we are capable of uniformly dispersing particles with sizes ranging from coarse mode particles (e.g., dust) to fine particulate matters (nano-sized particles) at controlled size distributions and concentrations, while maintaining stability.

TABLE I. Comparison of different existing chamber systems.

\begin{tabular}{|c|c|c|}
\hline Chamber systems & $\begin{array}{c}\text { Chamber } \\
\text { type/size (L) }\end{array}$ & $\begin{array}{c}\text { Exposure } \\
\text { duration (Hrs/day) }\end{array}$ \\
\hline Ye et al. ${ }^{38}$ & Nose only & $1-2$ \\
\hline Mainelis et al. ${ }^{19}$ & Nose only & 1 \\
\hline Ko et al. ${ }^{13}$ & 1 & 0.2 \\
\hline Kang et al..$^{15}$ & 6.3 & 6 \\
\hline Hougaard et al. ${ }^{16}$ & 18 & 1 \\
\hline Peng et al. ${ }^{35}$ & 540 & 24 \\
\hline
\end{tabular}

\section{CHAMBER DESCRIPTION}

\section{A. Clean air system}

Lab compressed air is passed through a filter system (Speedaire Compress Air Filter-4ZL51, Grainger, Illinois, USA) prior to entering an atomizer/particle disperser (Fig. 1). The filter system consists of silica gel (absorbs water moisture), activated carbon (absorbs organics), Hopcalite (absorbs CO), Purafil (absorbs NOx), and a high-efficiency particulate air (HEPA) filter (absorbs 99.97\% of airborne particles). The total flowrate of the nebulizer injection system is $6 \mathrm{l} / \mathrm{min}$, while the small scale powder disperser (SSPD) injection system flowrate ranges from 12 to $20 \mathrm{l} / \mathrm{min}$. When flushing the chamber with clean air before/after each experiment, organics, $\mathrm{CO}$, and NOx concentration were below the detection limit of the hydrocarbon/CO/NOx gas analyzer.

\section{B. Aerosol generation system}

The aerosol generation system consists of two parts, including a house-built atomizer for generating aerosol sprays from multiple liquid solutions and a small scale powder disperser for dispersing dry powder from the surface of a turntable.

\section{Atomizer for nanoparticles}

A stainless-steel atomizer generates aerosol from an ultrapure water solution of target pollutants. Compressed air passes through an orifice that creates an air jet which breaks up the solution, which is then sucked up via a reduction in static pressure, generating a continuous wet aerosol spray from the solution. ${ }^{20}$ The wet aerosol is then routed through a heated copper coil at $127 \mathrm{~F}$ to transform water moisture into vapor, which is absorbed when passed through a diffuser dryer filled with indicator silica gel, replaced daily. This is to provide a pure particle dose in the nano-size range since the nebulizer aerosol spray produces a particle size at the micron level. The dried aerosols are subsequently injected into the second component, the mouse chamber. The atomizer design continuously delivers nano-sized aerosol with consistent size distribution and mass concentration throughout the exposure period. The mass concentration is controlled through the concentration of aqueous solution. 


\section{Small scale powder disperser (SSPD)}

An SSPD from TSI (Model 3433, TSI, Minnesota, USA) was used to disperse target pollutants in powder forms, which are insoluble in water, as well as micron-sized particles from $0.5 \mu \mathrm{m}$ to $50 \mu \mathrm{m}$ efficiently. Powders were loaded on a turntable that rotates at speeds ranging from 0.25 to $3.3 \mathrm{rev} / \mathrm{h}$. A stainless-steel capillary positioned just above the turntable removes powder from the surface of a turntable; the shear forces created by two flows deagglomerates the powder, which enters an expansion cone and is exhausted from the instrument and then enters the chamber. In this design, the SSPD delivers a continuous powder aerosol dose for $4 \mathrm{~h}$ for each loading of powder on the turntable. Exposure times and mass concentrations are controlled by changing the rotation speed of the turntable.

\section{Chamber system}

The mouse chamber is made of 6 clear acrylic sheets with a thickness of $\frac{1}{4}$ in. The total chamber volume is approximately 5401 with external dimensions of $101.6 \times 81.3 \times 63.6 \mathrm{~cm}^{3}$ (length $\times$ width $\times$ height). Two porous aluminum plates were used to help deliver uniform dispersion by separating the aerosol inlet (upper left) and sampling ports (lower right). The large size of the chamber allows up to six mouse cages (carrying up to three mice each under normal laboratory conditions) to fit in simultaneously for exposure tests. A light-emitting diode (LED) warm light string attached to a timer switch simulates a light cycle for experimental mice daily by switching on at 7 a.m. and off at 7 p.m.

To avoid light contamination, the whole chamber is covered with a customized blackout cloth and a small detachable window allows observance of mice during the exposure tests. A $\frac{1}{4}$ in. inlet from the upper left of the chamber was used for injection, while four $\frac{1}{2}$ in. exhaust ports located in the lower right chamber ensured that the in-chamber pressure would not build up during aerosol injection. Another $\frac{1}{4}$ in. outlet located below the exhaust tubes was used for sampling monitoring. Before and after each test, the chamber was flushed with particle free air of at least ten chamber volumes to avoid contamination.

\section{Sample monitoring systems}

Three instruments were attached to the chamber sample port to monitor the experiments.

\section{Size distribution and concentration measurements}

Aerosol size distribution and concentration during the experiments are recorded by using two different instrument systems. The Scanning Mobility Particle Sizer (SMPS) (Model 3080 Electrostatic Classifier using Kr85, TSI, Minnesota, USA) and Condensation Particle Counter (CPC) (Model 3776, TSI, Minnesota, USA) system is used to measure particles in the range of $2 \mathrm{~nm}-1000 \mathrm{~nm}$, while the Laser Aerosol Particle Size Spectrometer (LAP) (TOPAS, Germany) provides information of particle size ranging from $0.2 \mu \mathrm{m}$ to $40 \mu \mathrm{m}$. The SMPS-CPC system is widely used as a standard method for characterization of particles smaller than $1 \mu \mathrm{m}$ in diameter with a high resolution of up to 167 channels. $^{21,22}$ The sheath flow rate of SMPS was set at 3 LPM, while the CPC aerosol flow rate was set at 0.3 LPM for a 10:1 ratio. The LAP served as a supplemental instrument for detecting micron sized particles with a high resolution of up to 128 channels.

\section{Total PM mass concentration measurements}

The DustTrak ${ }^{\mathrm{TM}}$ (TSI, Minnesota, USA) aerosol monitor provides real-time aerosol mass readings using a light-scattering laser photometer. When equipped with different size impactors, the DustTrak measures aerosol concentrations corresponding to PM1, PM2.5, or PM10, ranging from 0.001 to $400 \mathrm{mg} / \mathrm{m}^{3}$.

\section{TARGET POLLUTANTS}

Multiple target pollutants, either field collected samples (swine dust/Salton Sea samples) or industrial products (nanosilica/Alternaria/silica powder), were injected into the chamber through the aerosol generation system. While the dry silica powder with highest density (Fig. 2) was dispersed using the SSPD 3433, other targets were nebulized from aqueous solutions and their size distributions can be found in Fig. 6. The purpose of nebulizing targets that are soluble in water was to consistently produce nanosized particles with stable size distribution and mass concentration regardless of their density, instead of reproducing environmental particles in their original physical properties. All five particle suspensions in the chamber were of a size distribution to allow deep penetration into the lungs and even potential penetration into the bloodstream and extrapulmonary organs.

\section{A. Fungal extract solution}

The fungus Alternaria alternata is a common allergen, widespread in many indoor and outdoor habitats, found to thrive on various types of vegetation. Contact with this fungus is unavoidable, given that Alternaria produces thousands of spores per cubic meter of air. ${ }^{24,25}$ Alternaria poses a general health threat as one of the most abundant sources of aeroallergens known to trigger immune sensitization and as a primary risk factor for the development of asthma. Furthermore, exposure to Alternaria alternata in previously sensitized individuals is correlated with a severe increased risk of morbidity and a higher risk of fatal asthma attacks. ${ }^{24-27}$ In children raised in desert environments, natural exposure to Alternaria spores induces allergic rhinitis symptoms and serves as a major allergen causing

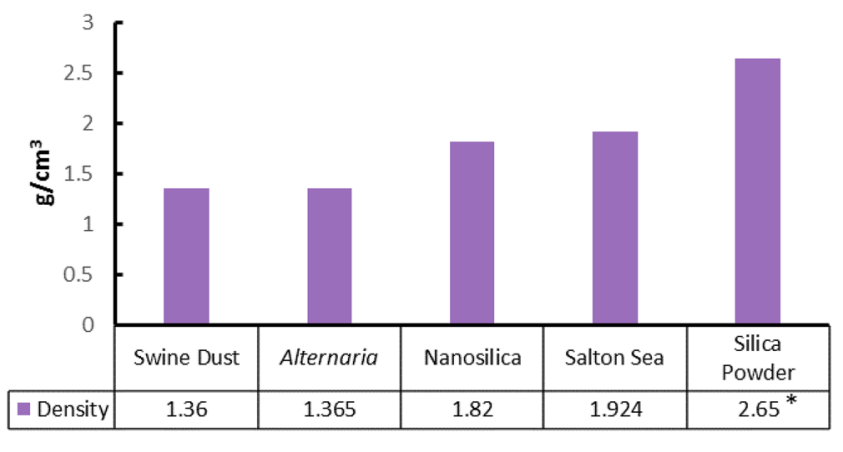

*Factory provided

FIG. 2. Densities of five target particle suspension in the environmental chamber. Density data were obtained using an Aerosol Particle Mass Analyzer (APM)/Scanning Mobility Particle Spectrometer (SMPS) setup, which has been modified to achieve higher transmission of particles and improved sampling frequency. ${ }^{23}$ 
juvenile allergic asthma. ${ }^{24-26,28,29}$ In this study, we nebulized an Alternaria extract solution and monitored the size distribution of Alternaria aerosol using the SMPS.

\section{B. Salton Sea dust}

Salton Sea-adjacent airborne particles were obtained by using passive collectors consisting of Teflon-coated round pans $(25.4 \mathrm{~cm}$ in diameter) filled with quartz marbles suspended from the pan bottom with Teflon mesh and capped with two overarching crossbraces covered in Tanglefoot to discourage roosting by birds. ${ }^{30}$ All materials in contact with dust (i.e., pan, marbles, and Teflon mesh) were pre-washed prior to installation using first bleach, then distilled $2 \mathrm{M} \mathrm{HCl}$, and finally distilled $3 \mathrm{M} \mathrm{HNO}_{3}$ with rinses of $>18.2 \mathrm{M} \Omega$ $\mathrm{cm}$ water between each reagent cleaning step. The collectors were deployed on $2.4 \mathrm{~m}$ tall wooden posts in open areas at each on the field sites to minimize local contributions of material from windsuspended soil (i.e., from saltation) and nearby trees. Collectors were deployed continuously from December 2015 through March 2017 at the Dos Palmas Preserve, at $33^{\circ} 29^{\prime} 22.1^{\prime \prime} \mathrm{N} 115^{\circ} 50^{\prime} 06.3^{\prime \prime} \mathrm{W}$. To recover dust samples from each collector in March 2017, we rinsed the marbles with $>18.2 \mathrm{M} \Omega \mathrm{cm}$ water into the Teflon-coated pan, removing the marbles and mesh, then transferring the water and dust suspension to pre-cleaned 11 LDPE Nalgene bottles. The samples were frozen and stored either at -20 or $4{ }^{\circ} \mathrm{C}$ until use.

\section{Swine facility dust}

Dusts were also collected from swine concentrated animal feeding operations and prepared into a sterile aqueous extract solution. $^{31}$ Briefly, settled surface dusts were collected off horizontal surfaces within swine confinement facilities (500-700 animals per facility). Collections were obtained from surfaces located approximately three feet above the floor of the facilities. Dusts obtained in this manner are routinely characterized for major determinants, including endotoxin and muramic acid concentrations to determine relative uniformity of samples across collection facilities and seasons. Detailed analyses of these and other determinants have been previously published. ${ }^{32-34}$ Following collection, dust samples were placed in a buffered saline solution at $100 \mathrm{mg} / \mathrm{ml}$ concentration. Following a 1-h incubation, samples were centrifuged to pellet all course particles and the supernatant fractions were filtered through a $0.22 \mu \mathrm{m}$ pore filter. Aqueous extracts obtained following filtration were considered a $100 \%$ stock concentration and were frozen at $-20{ }^{\circ} \mathrm{C}$ until use.

\section{Nanosilica and ground silica powder}

The $100 \mathrm{~nm}$ non-functionalized NanoXact ${ }^{\mathrm{TM}}$ silica (nanoComposix, Inc, California, USA) are produced via the condensation of silanes from nanoparticles that consists of an amorphous network of silicon and oxygen, and the particles are monodisperse with narrow size distributions. The particles are readily suspended in polar solvents such as water and ethanol.

The MIN-U-SIL 5 GROUND SILICA powder (Western Reserve Chemical, Ohio, USA) is a natural, fine ground silica with high purity. The consistent $\mathrm{pH}$ and narrow size distributions allow very high loading with minimal effect on viscosity and cure rate versus synthetic silicas. The high quality, inert, white crystalline silica is
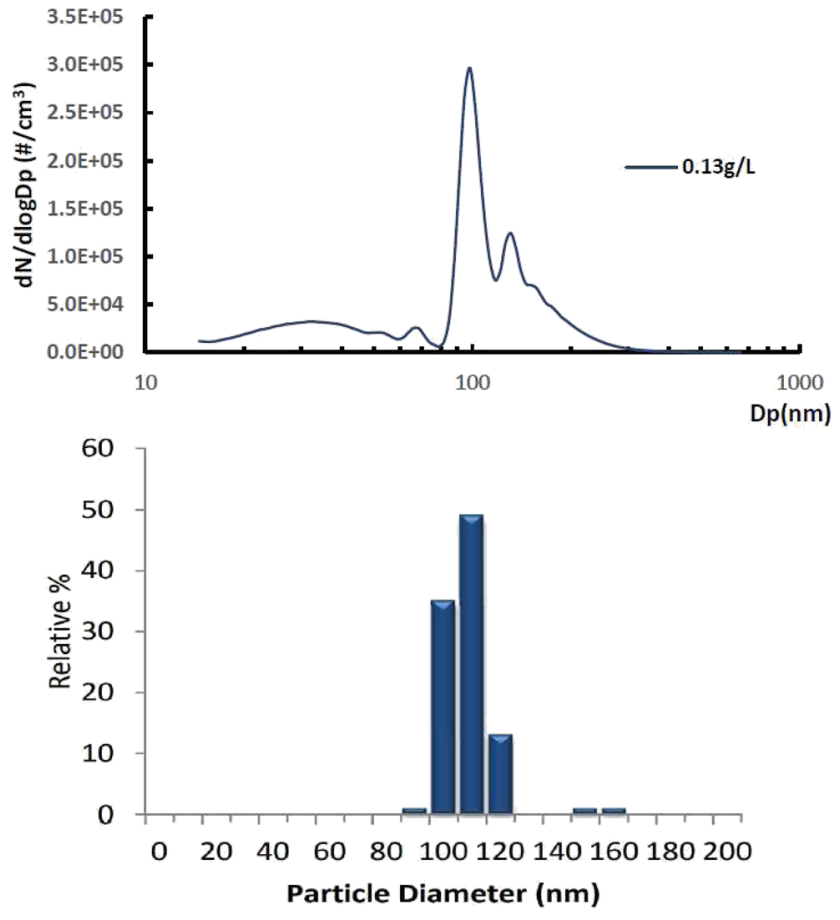

FIG. 3. Size distribution comparison of factory provided and lab nebulized nanosilica size distribution.

available in five size distributions $(5,10,15,30$, and $40 \mu \mathrm{m}$ topsize). The comparison of the factory provided silica particle distribution and the lab nebulized distribution can be found in Fig. 3.

\section{RESULTS AND DISCUSSIONS}

\section{A. Mass concentration across the chamber}

Figure 4 shows the PM2.5 concentration of aerosolized ammonium nitrate $\left(\mathrm{NH}_{4} \mathrm{NO}_{3}\right)$ solution in six different locations of the chamber plate with a standard deviation of 1.97. The DustTrak was placed inside the chamber at six locations, with the sampling port at the height of $\sim 10 \mathrm{~cm}$ to simulate mouse breathing conditions in the cages. Overall, the chamber could deliver uniform dispersion within

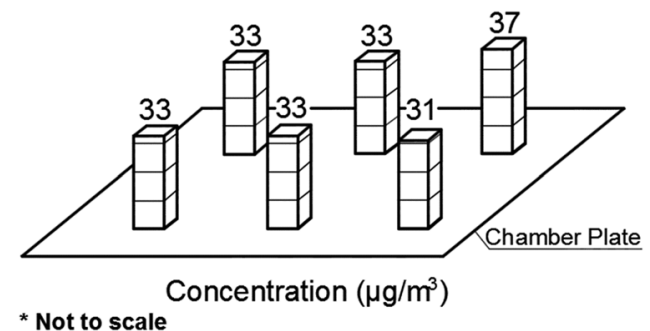

FIG. 4. Mass concentration across the chamber. ${ }^{35}$ Reproduced with permission from Peng X et al., ASN Neuro 10, 175909141878230 (2018). Copyright 2018 ASN Neuro. 


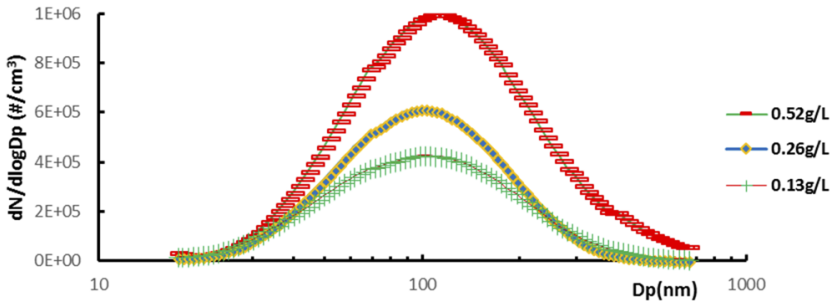

FIG. 5. Size distribution of Alternaria aerosol in three different levels. The $Y$ axis stands for particle number concentration $\mathrm{dN} / \mathrm{dlogDp}\left(\# / \mathrm{cm}^{3}\right)$, while the $X$ axis represents particle size on a logarithmic scale.

the two porous aluminum plates that separated the aerosol inlet and the exhaust.

\section{B. Nebulized aerosol suspension in different levels}

The concentration of aerosol suspension in the chamber (Fig. 5) could be controlled through changing the aqueous solution concentration, resulting in different levels of mass concentration. Three different aqueous solution concentrations of Alternaria extract of $0.13 \mathrm{~g} / \mathrm{l}, 0.26 \mathrm{~g} / \mathrm{l}$, and $0.52 \mathrm{~g} / \mathrm{l}$ were nebulized into the chamber through an atomizer. The size distribution was acquired through the SMPS. The higher solution concentration leads to the higher total number concentration in the chamber aerosol suspension without significantly changing the particle mode diameter of $100 \mathrm{~nm}$.

Four different types of target pollutants were nebulized into the chamber at a controlled number/mass concentration (Figs. 6 and 7). While the mode diameters of these aerosol range from $53 \mathrm{~nm}$ to
$109 \mathrm{~nm}$, all of them can pass from the lungs into the bloodstream and extra-pulmonary organs. The higher number concentration does not always result in the higher mass concentration since larger size particles dominate the total mass concentration. For example, the swine dust extract had a much lower total mass concentration than that of the Alternaria extract (Fig. 7) even though it had a significantly higher number concentration (Fig. 6).

The mass concentration could be controlled from the microgram per cubic meter range to milligram per cubic meter range (Fig. 7). The chamber was saturated with continuous aerosol injection and remains consistent throughout the whole experiment, providing a much more effective and protracted dose delivery than the intranasal method. We have conducted separate tests with animal subjects for a full week exposure. For the 3 exposure tests where the target concentration was $1.5 \mathrm{mg} / \mathrm{m}^{3}$, we measured an average concentration of $1.47 \pm 0.03 \mathrm{mg} / \mathrm{m}^{3}$. For the 8 exposure tests where the target concentration was $1.3 \mathrm{mg} / \mathrm{m}^{3}$, we measured an average concentration of $1.2 \pm 0.13 \mathrm{mg} / \mathrm{m}^{3}$.

\section{Powder-silica aerosol from SSPD 3433}

Occupational exposures in different trades range from the lowest on operation engineers $\left(0.075-0.720 \mathrm{mg} / \mathrm{m}^{3}\right)$ to the highest on painters $\left(1.28-13.5 \mathrm{mg} / \mathrm{m}^{3}\right),{ }^{36}$ which significantly exceeds the US Occupational Exposure Limit (OEL) of $0.05 \mathrm{mg} / \mathrm{m}^{3}$ for respirable silica. ${ }^{37}$

To simulate exposures to respirable silica among construction sites in the USA, two 4-h silica doses were injected into the chamber each day (Fig. 8). The first dose was given from 8 a.m. to 12 p.m., while the second dose was given from 4 p.m. to 8 p.m. Figure 8 shows ten doses injected over 5 days with an average dose
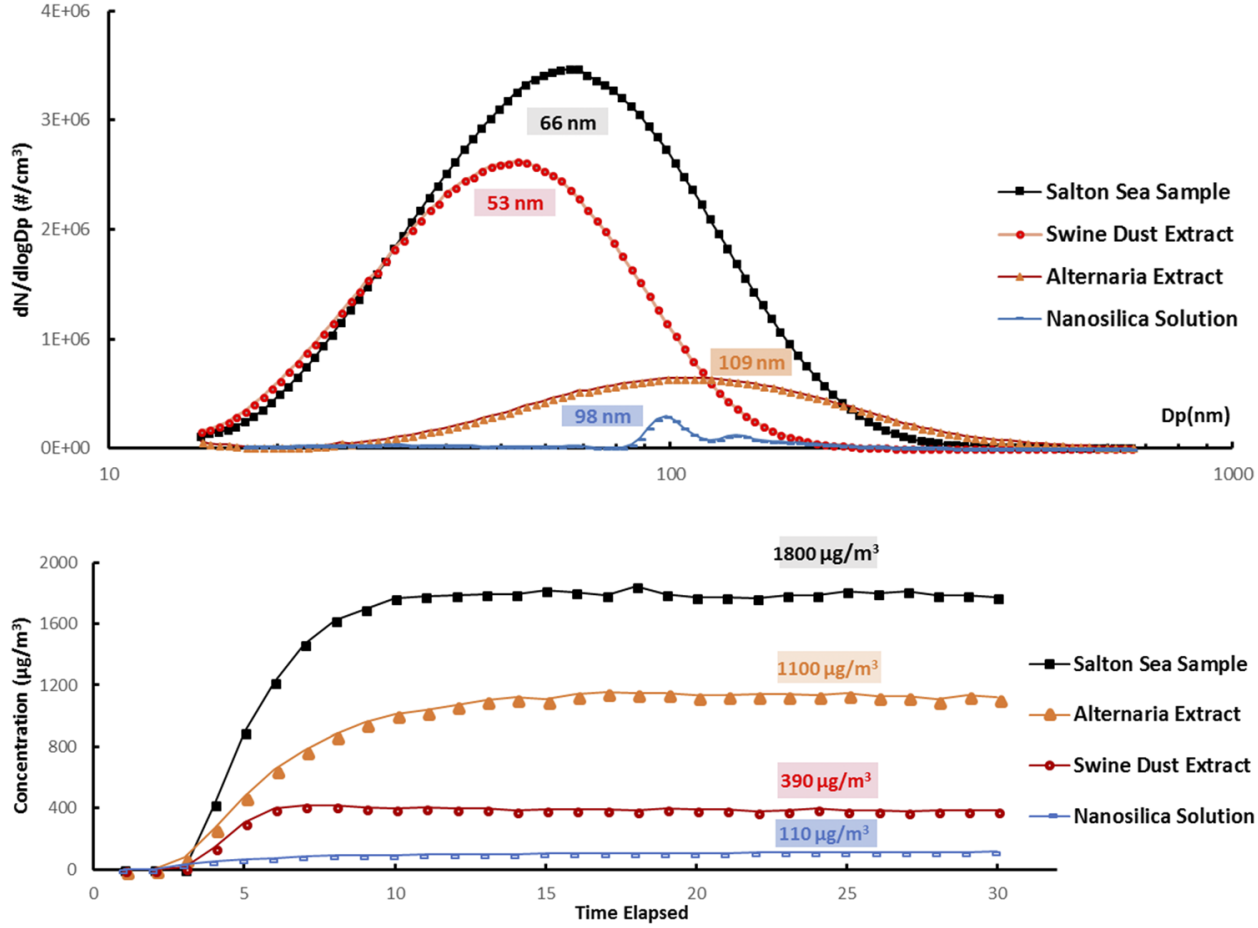

FIG. 6. Size distribution comparison of four different nebulized target pollutants from SMPS.

FIG. 7. Consistent mass concentration of target pollutants over time. 


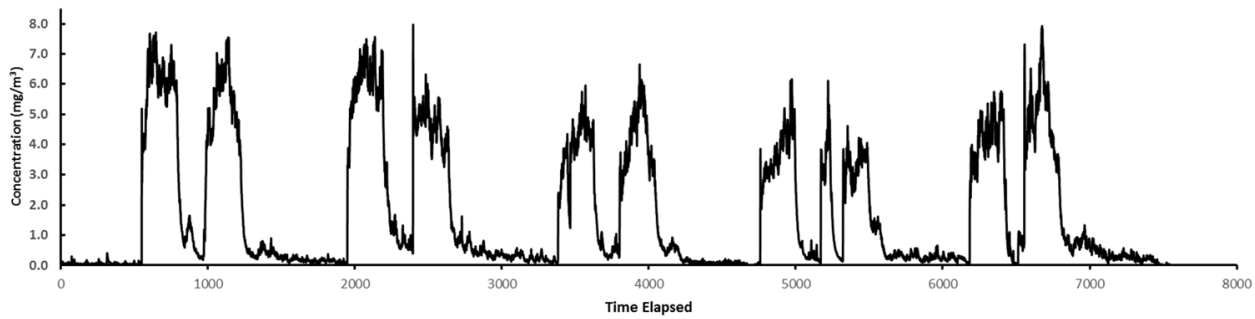

FIG. 8. Mass concentration of powder silica aerosol throughout the five-day exposure.

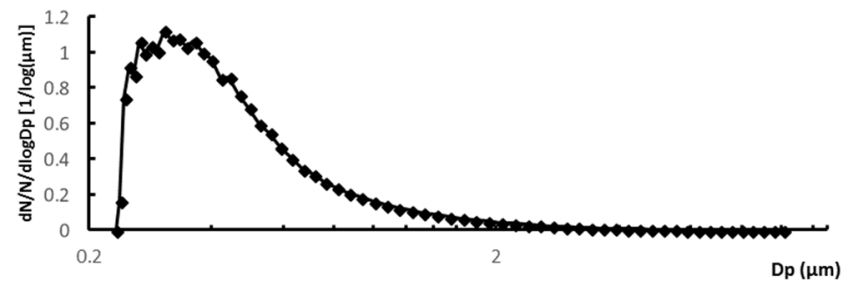

FIG. 9. Size distribution of powder silica aerosol. The vertical axis stands for particle number distribution $\mathrm{dN} / \mathrm{N} / \mathrm{dlogDp}[1 / \log (\mu \mathrm{m})]$, while the horizontal axis represents particle size on a logarithmic scale.

concentration of around $5 \mathrm{mg} / \mathrm{m}^{3}$ and the overall average concentration of $1.43 \mathrm{mg} / \mathrm{m}^{3}$. Figure 9 shows the size distribution of dispersed silica powder with a mode of around $306 \mathrm{~nm}$.

\section{CONCLUSION}

Here we developed a large-scale multipurpose animal exposure chamber for health effect investigation of air pollutants. Compared to other chamber systems featuring nose-only or activity-limited whole-body exposure, this system provides continuous exposure through the natural inhalation route at controlled concentration, size distribution, and duration for chronic, sub-chronic, and acute epidemiological studies. Our method is also easily reproducible and has the potential to mimic the real atmospheric environment by adding multiple air contaminants at the same time for health investigations.

\section{ACKNOWLEDGMENTS}

These studies were funded by grants from the UCR Office of Research, as well as No. NSF EAR-1744089. We would like to thank Chen Le for assistance with the chamber system schematic design and Chelsea Carey, Taryn Barsotti, and Geoffrey Logan who assisted with the collector setup or processing of the samples in the lab. We would also like to thank Dr. Debra Romberger, MD, University of Nebraska Medical Center, for the swine facility dusts.

\section{REFERENCES}

${ }^{1}$ L. H. Ziska and F. A. Caulfield, "Rising $\mathrm{Co}_{2}$ and pollen production of common ragweed (ambrosia artemisiifolia 1.), a known allergy-inducing species: Implications for public health," Funct. Plant Biol. 27, 893-898 (2000).

${ }^{2}$ C. Traidl-Hoffmann, A. Kasche, A. Menzel, T. Jakob, M. Thiel, J. Ring, and H. Behrendt, "Impact of pollen on human health: More than allergen carriers?," Int. Arch. Allergy Immunol. 131, 1-13 (2003).
${ }^{3}$ K. Onishi, Y. Kurosaki, S. Otani, A. Yoshida, N. Sugimoto, and Y. Kurozawa, "Atmospheric transport route determines components of asian dust and health effects in Japan," Atmos. Environ. 49, 94-102 (2012).

${ }^{4}$ N. Li, M. Hao, R. F. Phalen, W. C. Hinds, and A. E. Nel, "Particulate air pollutants and asthma: A paradigm for the role of oxidative stress in pm-induced adverse health effects," Clin. Immunol. 109, 250-265 (2003).

${ }^{5} \mathrm{~N}$. Li, T. Xia, and A. E. Nel, "The role of oxidative stress in ambient particulate matter-induced lung diseases and its implications in the toxicity of engineered nanoparticles," Free Radical Biol. Med. 44, 1689-1699 (2008).

${ }^{6}$ C. A. Pope III and D. W. Dockery, "Health effects of fine particulate air pollution: Lines that connect," J. Air Waste Manage. Assoc. 56, 709-742 (2006).

${ }^{7}$ U. Gehring, J. Heinrich, U. Krämer, V. Grote, M. Hochadel, D. Sugiri, M. Kraft, K. Rauchfuss, H. G. Eberwein, H.-E. Wichmann et al., "Long-term exposure to ambient air pollution and cardiopulmonary mortality in women," Epidemiology 17, 545-551 (2006).

${ }^{8}$ G. Hoek, R. M. Krishnan, R. Beelen, A. Peters, B. Ostro, B. Brunekreef, and J. D. Kaufman, "Long-term air pollution exposure and cardio-respiratory mortality: A review," Environ. Health 12, 43 (2013).

${ }^{9}$ O. Raaschou-Nielsen, Z. J. Andersen, R. Beelen, E. Samoli, M. Stafoggia, G. Weinmayr, B. Hoffmann, P. Fischer, M. J. Nieuwenhuijsen, B. Brunekreef et al., "Air pollution and lung cancer incidence in 17 European cohorts: Prospective analyses from the European study of cohorts for air pollution effects (escape)," Lancet Oncol. 14, 813-822 (2013).

${ }^{10}$ M. R. Miller, J. B. Raftis, J. P. Langrish, S. G. McLean, P. Samutrtai, S. P. Connell, S. Wilson, A. T. Vesey, P. H. Fokkens, A. J. F. Boere et al., "Inhaled nanoparticles accumulate at sites of vascular disease," ACS Nano 11, 4542-4552 (2017).

${ }^{11}$ T. A. Doherty, N. Khorram, K. Sugimoto, D. Sheppard, P. Rosenthal, J. Y. Cho, A. Pham, M. Miller, M. Croft, and D. H. Broide, "Alternaria induces STAT6dependent acute airway Eosinophilia and epithelial FIZZ1 expression that promotes airway fibrosis and epithelial thickness," J. Immunol. 188, 2622-2629 (2012).

${ }^{12}$ W. Zhou, S. Toki, J. Zhang, K. Goleniewksa, D. C. Newcomb, J. Y. Cephus, D. E. Dulek, M. H. Bloodworth, M. T. Stier, V. Polosuhkin et al., "Prostaglandin I2 signaling and inhibition of group 2 innate lymphoid cell responses," Am. J. Respir. Crit. Care Med. 193, 31-42 (2016).

${ }^{13}$ M.-T. Ko, S.-C. Huang, and H.-Y. Kang, "Establishment and characterization of an experimental mouse model of allergic rhinitis," Arch. Oto-Rhino-Laryngol. 272, 1149-1155 (2015).

${ }^{14}$ R. E. Barnewall, E. M. Benson, M. A. Brown, D. A. Fisher, A. S. Lindsay, A. A. Simmons, and M. S. Anderson, "Characterization of a large animal aerosol exposure system for aerosolizing four strains of Burkholderia Pseudomallei," J. Aerosol Sci. 84, 21-38 (2015).

${ }^{15}$ S. S. Kang, M. Cole, S. Lee, and C. Rivier, "Development of individual alcohol inhalation chambers for mice: Validation in a model of prenatal alcohol," Alcohol.: Clin. Exp. Res. 28, 1549-1556 (2004).

${ }^{16}$ K. S. Hougaard, K. A. Jensen, P. Nordly, C. Taxvig, U. Vogel, A. T. Saber, and H. Wallin, "Effects of prenatal exposure to diesel exhaust particles on postnatal development, behavior, genotoxicity and inflammation in mice," Part. Fibre Toxicol. 5, 3 (2008)

${ }^{17}$ J. L. Mauderly, "Respiration of F344 rats in nose-only inhalation exposure tubes," J. Appl. Toxicol. 6, 25-30 (1986). 
${ }^{18}$ J. Kaur, P. Muttil, R. K. Verma, K. Kumar, A. B. Yadav, R. Sharma, and A. Misra, "A hand-held apparatus for 'nose-only' exposure of mice to inhalable microparticles as a dry powder inhalation targeting lung and airway macrophages," Eur. J. Pharm. Sci. 34, 56-65 (2008).

${ }^{19}$ G. Mainelis, S. Seshadri, O. Garbuzenko, T. Han, Z. Wang, and T. Minko, "Characterization and application of a nose-only exposure chamber for inhalation delivery of liposomal drugs and nucleic acids to mice," J. Aerosol Med. Pulm. Drug Delivery 26, 345-354 (2013).

${ }^{20} \mathrm{~K}$. May, "The collision nebulizer: Description, performance and application," J. Aerosol Sci. 4, 235-243 (1973).

${ }^{21}$ S. C. Wang and R. C. Flagan, "Scanning electrical mobility spectrometer," Aerosol Sci. Technol. 13, 230-240 (1990).

${ }^{22}$ G. W. Mulholland, M. K. Donnelly, C. R. Hagwood, S. R. Kukuck, V. A. Hackley, and D. Y. Pui, "Measurement of $100 \mathrm{~nm}$ and $60 \mathrm{~nm}$ particle standards by differential mobility analysis," J. Res. Natl. Inst. Stand. Technol. 111, 257 (2006).

${ }^{23}$ Q. G. Malloy, S. Nakao, L. Qi, R. Austin, C. Stothers, H. Hagino, and D. R. Cocker III, "Real-time aerosol density determination utilizing a modified scanning mobility particle sizer-Aerosol particle mass analyzer system," Aerosol Sci. Technol. 43, 673-678 (2009).

${ }^{24}$ M. F. Gabriel, I. Postigo, C. T. Tomaz, and J. Martínez, "Alternaria alternata allergens: Markers of exposure, phylogeny and risk of fungi-induced respiratory allergy," Environ. Int. 89, 71-80 (2016).

${ }^{25}$ A. P. Knutsen, R. K. Bush, J. G. Demain, D. W. Denning, A. Dixit, A. Fairs, P. A. Greenberger, B. Kariuki, H. Kita, V. P. Kurup et al., "Fungi and allergic lower respiratory tract diseases," J. Allergy Clin. Immunol. 129, 280-291 (2012).

${ }^{26}$ R. K. Bush and J. J. Prochnau, "Alternaria-induced asthma," J. Allergy Clin. Immunol. 113, 227-234 (2004).

${ }^{27}$ A. Vianello, M. Caminati, M. Crivellaro, R. El Mazloum, R. Snenghi, M. Schiappoli, A. Dama, A. Rossi, G. Festi, M. R. Marchi et al., "Fatal asthma; is it still an epidemic?," World Allergy Organ. J. 9, 42 (2016).

${ }^{28}$ M. Andersson, S. Downs, T. Mitakakis, J. Leuppi, and G. Marks, "Natural exposure to alternaria spores induces allergic rhinitis symptoms in sensitized children," Pediatr. Allergy Immunol. 14, 100-105 (2003).
${ }^{29}$ M. Halonen, D. A. Stern, A. L. Wright, L. M. Taussig, and F. D. Martinez, "Alternaria as a major allergen for asthma in children raised in a desert environment,” Am. J. Respir. Crit. Care Med. 155, 1356-1361 (1997).

${ }^{30}$ S. Aciego, C. Riebe, S. Hart, M. Blakowski, C. Carey, S. Aarons, N. Dove, J. Botthoff, K. Sims, and E. Aronson, "Dust outpaces bedrock in nutrient supply to montane forest ecosystems," Nat. Commun. 8, 14800 (2017).

${ }^{31}$ D. Romberger, V. Bodlak, S. Von Essen, T. Mathisen, and T. Wyatt, "Hog barn dust extract stimulates Il-8 and Il-6 release in human bronchial epithelial cells via PKC activation," J. Appl. Physiol. 93, 289-296 (2002).

${ }^{32}$ J. A. Poole, N. E. Alexis, C. Parks, A. K. MacInnes, M. J. Gentry-Nielsen, P. D. Fey, L. Larsson, D. Allen-Gipson, S. G. Von Essen, and D. J. Romberger, "Repetitive organic dust exposure in vitro impairs macrophage differentiation and function," J. Allergy Clin. Immunol. 122, 375-382 (2008).

${ }^{33}$ J. A. Poole, G. P. Dooley, R. Saito, A. M. Burrell, K. L. Bailey, D. J. Romberger, J. Mehaffy, and S. J. Reynolds, "Muramic acid, endotoxin, 3-hydroxy fatty acids, and ergosterol content explain monocyte and epithelial cell inflammatory responses to agricultural dusts," J. Toxicol. Environ. Health, Part A 73, 684-700 (2010).

${ }^{34}$ R. J. Boissy, D. J. Romberger, W. A. Roughead, L. Weissenburger-Moser, J. A. Poole, and T. D. LeVan, "Shotgun pyrosequencing metagenomic analyses of dusts from swine confinement and grain facilities," PLoS One 9, e95578 (2014). ${ }^{35}$ X. Peng, A. M. Madany, J. C. Jang, J. M. Valdez, Z. Rivas, A. C. Burr, Y. Y. Grinberg, T. M. Nordgren, M. G. Nair, D. Cocker et al., "Continuous inhalation exposure to fungal allergen particulates induces lung inflammation while reducing innate immune molecule expression in the brainstem," ASN Neuro 10, 175909141878230 (2018).

${ }^{36}$ S. Rappaport, M. Goldberg, P. Susi, and R. F. Herrick, "Excessive exposure to silica in the us construction industry," Ann. Occup. Hyg. 47, 111-122 (2003).

${ }^{37}$ K. D. Linch, W. E. Miller, R. B. Althouse, D. W. Groce, and J. M. Hale, "Surveillance of respirable crystalline silica dust using Osha compliance data (1979-1995)," Am. J. Ind. Med. 34, 547-558 (1998).

${ }^{38}$ J. Ye, S. Salehi, M. L. North, A. M. Portelli, C. W. Chow, and A. W. Chan, "Development of a novel simulation reactor for chronic exposure to atmospheric particulate matter," Sci. Rep. 7, 42317 (2017). 